\title{
Microstructural analysis of demineralized primary enamel after in vitro toothbrushing
}

\section{Análise microestrutural do esmalte decíduo desmineralizado após escovação dentária in vitro}

\author{
Aline de Almeida Neves* \\ Rodolfo de Almeida Castro* \\ Eduardo Tavares Coutinho** \\ Laura Guimarães Primo***
}

\begin{abstract}
The aim of this study was to investigate, in vitro, the morphological characteristics of demineralized primary enamel subjected to brushing with a dentifrice with or without fluoride. In order to do so, 32 enamel blocks were divided in 4 different groups containing 8 blocks each. They were separately immersed in artificial saliva for 15 days. The experimental groups were: $\mathrm{C}$ - control; E - submitted to etching with $37 \%$ phosphoric acid gel (30 s); EB - submitted to etching and brushing 3 times a day with a non-fluoridated dentifrice; $\mathrm{EBF}=$ submitted to etching and brushing 3 times a day with a fluoridated dentifrice. The toothbrushing force was standardized at $0.2 \mathrm{kgf}$ and 15 double strokes were performed on each block. After the experimental period, the samples were prepared and examined under SEM. The control group (C) showed a smooth surface, presenting scratches caused by habitual toothbrushing. The etched samples (E) exhibited different degrees of surface disintegration, but the pattern of acid etching was predominantly the type II dissolution. The brushed surfaces were smooth, with elevations which corresponded to the exposure of Tomes' process pits and depressions which corresponded to interrod enamel. Particles resembling calcium carbonate were found in the most protected parts of the grooves. No morphological differences were observed between brushing with fluoridated (EBF) and non-fluoridated (EB) dentifrice. The results suggest that the mechanical abrasion caused by brushing demineralized enamel with dentifrice smoothes the rough etched surface, and the presence of fluoride does not cause morphological modifications in this pattern.
\end{abstract}

UNITERMS: Tooth, deciduous; Dental enamel/ultrastructure; Tooth demineralization.

\begin{abstract}
RESUMO: O objetivo do estudo foi investigar as características morfológicas do esmalte decíduo desmineralizado submetido à escovação com dentifrício fluoretado ou não fluoretado. Para isto, 32 blocos de esmalte foram separados em 4 grupos diferentes, contendo 8 elementos cada que foram imersos em saliva artificial por 15 dias: $\mathrm{C}=$ controle; $\mathrm{E}=\mathrm{ata}-$ cado com gel de ácido fosfórico a $37 \%$ por 30 segundos; EB = atacado e escovado 3 vezes ao dia com dentifrício não fluoretado; $\mathrm{EBF}$ = atacado e escovado 3 vezes ao dia com dentifrício fluoretado. A escovação foi padronizada em 0,2 kgf e 15 movimentos de vai-e-vem foram executados em cada bloco. Após o periodo experimental, as amostras foram preparadas e examinadas no MEV. O grupo controle (C) apresentou lisura superficial e riscos causados pela escovação habitual; as amostras atacadas (E) apresentaram diferentes graus de desintegração superficial, porém o padrão de ataque ácido foi predominantemente a dissolução do tipo II. As superfícies escovadas apresentaram-se alisadas, com exposição das elevações correspondentes aos processos de Tomes e as depressões de esmalte interprismático. Partículas semelhantes a carbonato de cálcio foram encontradas nas partes mais protegidas das depressões. Não houve diferença quando os grupos foram escovados com dentifrício fluoretado (EBF) e dentifrício sem fluoreto (EB). Os resultados sugerem que a abrasão mecânica da escovação com dentifrício sobre o esmalte desmineralizado alisa a superficie rugosa causada pelo condicionamento ácido e que a presença do fluoreto não altera morfologicamente este padrão. UNITERMOS: Dente decíduo; Esmalte dentário/ultra-estrutura; Desmineralização do dente.
\end{abstract}

\section{INTRODUCTION}

The tooth enamel surface is constantly exposed to great acidic challenges, such as those caused by undisturbed plaque accumulations in stagnation areas or by etching techniques in restorative or orthodontic procedures. The morphology of the enamel affected by each of these factors is characterized by direct dissolution and roughness of the outer surfaces ${ }^{3,14}$.

\footnotetext{
${ }^{*}$ Graduate students (MSD); ***MSD, PhD, Assistant Professor - Department of Pediatric Dentistry and Orthodontics, School of Dentistry, Federal University of Rio de Janeiro, Brazil.

**Graduate student (MSc), Department of Materials Science and Metallurgy, Pontifical Catholic University, Rio de Janeiro, Brazil.
} 
Neves A de A, Castro R de A, Coutinho ET, Primo LG. Microstructural analysis of demineralized primary enamel after in vitro toothbrushing. Pesqui Odontol Bras 2002;16(2):137-143.

Active incipient enamel caries lesions are one of the frequent clinical situations that require nonoperative treatment; comparatively, the fate of etched enamel surfaces that are left uncovered, exposed to the oral environment, is still a matter of discussion in the literature. The effect of remineralizing agents ${ }^{19}$, professional prophylaxis ${ }^{8}$ and of the abrasion caused by brushing with dentifrice ${ }^{18}$ over these demineralized surfaces has been extensively studied. Fluoride is said to enhance remineralization, which, in turn, means recovery of demineralized enamel ${ }^{20}$. Although in the presence of mechanical cleaning procedures fluoride is known to promote the arrest and regression of carious lesions $^{13,23}$, the effects of fluoride on the morphology of demineralized enamel has not yet been verified.

The aim of this study was to observe, using the scanning electron microscope (SEM), the morphology of demineralized primary enamel after a controlled period of toothbrushing with fluoridated and non-fluoridated dentifrices, in vitro.

\section{MATERIALS AND METHODS}

Eight second primary lower molars were selected from a bulk of extracted primary teeth collected at the Pediatric Dental Clinic, Federal University of Rio de Janeiro. The teeth were caries-free and had no other gross surface defects. They were kept in $4 \%$ aqueous formalin solution $(\mathrm{pH} 7.0)$ until the beginning of the experiment. The teeth were washed in distilled water and cut into six smooth-surface sections, in buccolingual direction ( $\mathrm{n}=48$ blocks), with a carborundum disc.

The enamel blocks were subsequently positioned over a vinyl polysiloxane (3M Express STD Firmer Set) standardized matrix with the aid of a

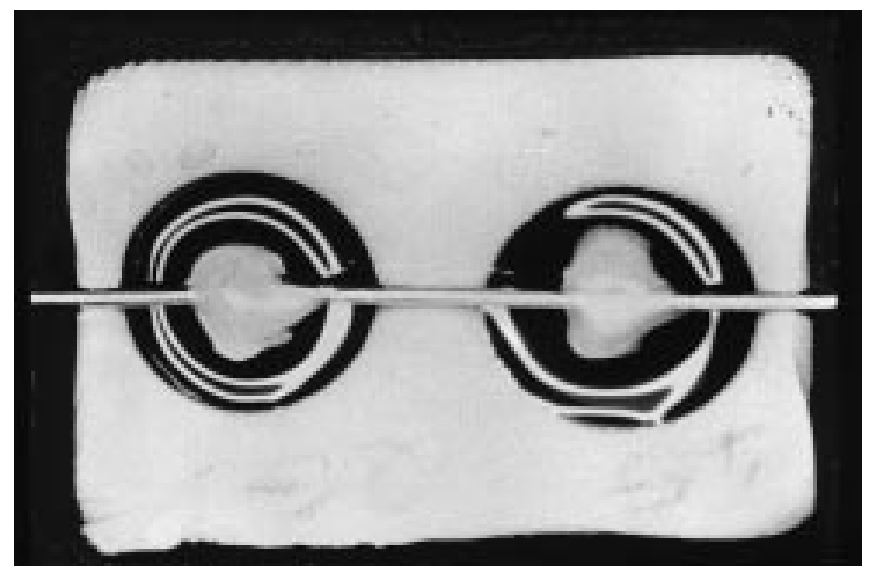

FIGURE 1 - Vinyl polysiloxane standardized base with enamel blocks positioned, by means of an orthodontic wire, in a resin-filled spot. 5-centemeter-long orthodontic wire. The matrix was filled with epoxy resin (XGY 1109 and HY 850) and stored at room temperature for 24 hours to allow for resin polymerization (Figure 1). Each block was mounted over the resin, with the outer enamel surface exposed.

Each block was pumiced with a rotating rubber cup for $30 \mathrm{~s}$ and washed in distilled water for $10 \mathrm{~s}$. After compressed air drying, the enamel blocks were examined under a stereomicroscope $(10 \mathrm{X}$ magnification) for surface defects. Thirty-two samples were selected and randomly assigned to 4 different groups: C - control (not etched); E - etched with 37\% phosphoric acid gel (Dentsply - Caulk) for 30 seconds, EB - etched as described in Group $\mathrm{E}$ and brushed with a non-fluoridated dentifrice (Phillips - The Sydney Ross Co.); EBF - etched as described in Group E and brushed with a fluoridated dentifrice (Philips 2 - Sydney Ross Co., 1,200 ppm MFP). The abrasive component of the dentifrices was calcium carbonate.

The groups were separately immersed in $60 \mathrm{ml}$ of artificial saliva $(\mathrm{KCl}-0.96 \mathrm{mM} ; \mathrm{NaCl}-0.674 \mathrm{mM}$; $\mathrm{MgCl}_{2} \mathrm{H}_{2} \mathrm{O}$ - $0.0408 \mathrm{mM} ; \mathrm{CaCl}_{2} \mathrm{H}_{2} \mathrm{O}-0.1168 \mathrm{mM}$; $\mathrm{K}_{2} \mathrm{H}_{2}\left(\mathrm{PO}_{4}\right)_{2}-0.274 \mathrm{mM} ; 0.8 \%$ carboxymetylcellulose, pH 7.0 - School of Pharmacy, Federal University of Rio de Janeiro) for 15 days. The samples from groups EB and EBF were removed from the saliva three times a day, with a minimum 3-hour interval, and brushed with a toothbrush (Oral B Indicator Soft 35). The toothbrushing force was standardized at $0.2 \mathrm{kgf}$ by means of a dynamometer coupled to a small hole carved on the toothbrush (Figure 2). At each brushing period, 15 double strokes were performed on each enamel block previously painted with a thin pellicle of dentifrice. After brushing, the blocks were rinsed in water, dried with high-com-

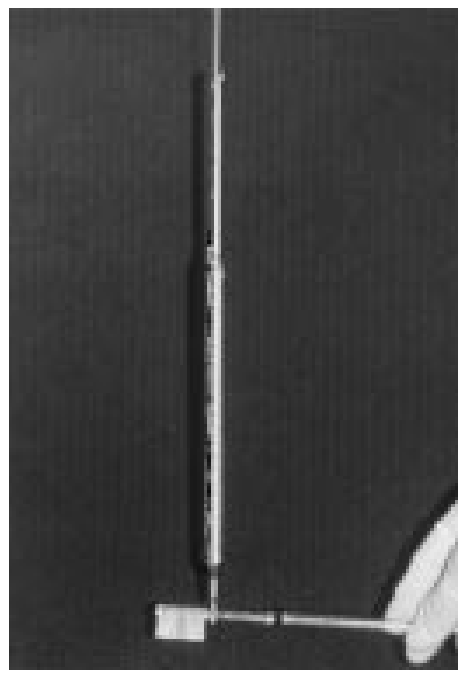

FIGURE 2 -

Dinamometer coupled to the toothbrush for the standardization of the toothbrushing force in $0.2 \mathrm{kgf}$. 
Neves A de A, Castro R de A, Coutinho ET, Primo LG. Microstructural analysis of demineralized primary enamel after in vitro toothbrushing. Pesqui Odontol Bras 2002;16(2):137-143.

pressed air and put back in the artificial saliva. A toothbrush was used for each brushed group during the experimental phase. The enamel blocks of groups $\mathrm{C}$ and $\mathrm{E}$ remained immersed in the artificial saliva throughout the 15 days.

At the end of the experimental phase, the samples were washed in distilled water for 2 minutes, dried at room temperature, sputter-coated with gold, and visualized by means of SEM at $20 \mathrm{kV}$ (Zeiss DSM 960, Germany). Electronmicrographs were obtained, and a descriptive analysis was carried out. The typical features observed are described and illustrated in Figures 3 to 6 .

\section{RESULTS}

Figure 3 shows the results of the control Group. The surface is generally smooth, while various scratches can be observed in a specific direction.
The samples subjected to acid etching presented direct dissolution of the surface. The lower magnification (Figure 4A) revealed an extensively eroded enamel surface. The higher magnification showed enhanced porosity and prism irregularities caused by the etching procedures. The pattern of dissolution, in the majority of the surfaces, was classified $^{21}$ as type II. Figures 5 and 6 show typical features found in the groups brushed with non-fluoridated (EB) and fluoridated dentifrices (EBF), respectively. It is possible to note a general leveling and smoothening of the samples in lower magnification, with exposure of Tomes' process pits (Figures 5B and 6B) separated by the smoothened interrod enamel of the underlying enamel layer (Figures 5B and 6B). Small particles, resembling insoluble remnants of the components of dentifrices were found, especially in the most pro-
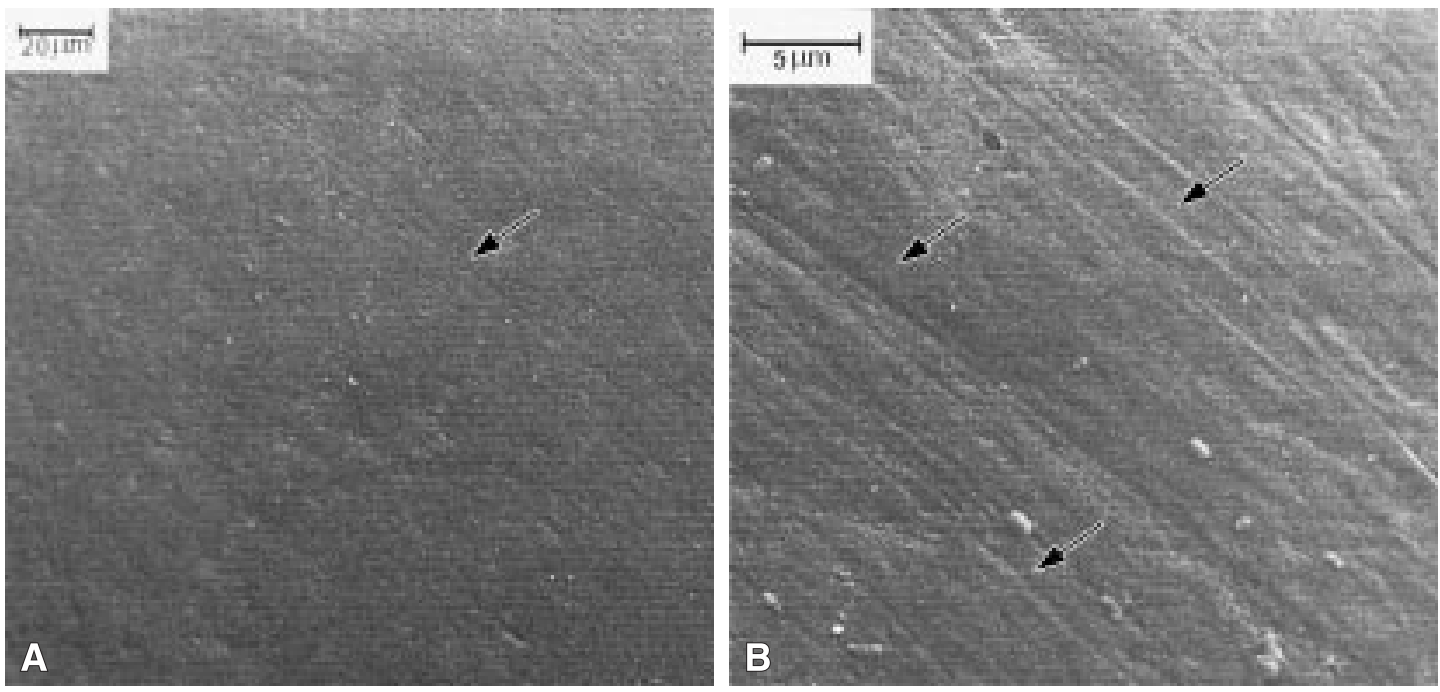

FIGURE 3 - Enamel from the control group $(\mathrm{C})$ visualized under SEM. The surface is generally smooth, presenting with some scratches caused by the toothbrushing habits of the child (arrows). A) $500 \mathrm{X}$; B) 3,000 X.
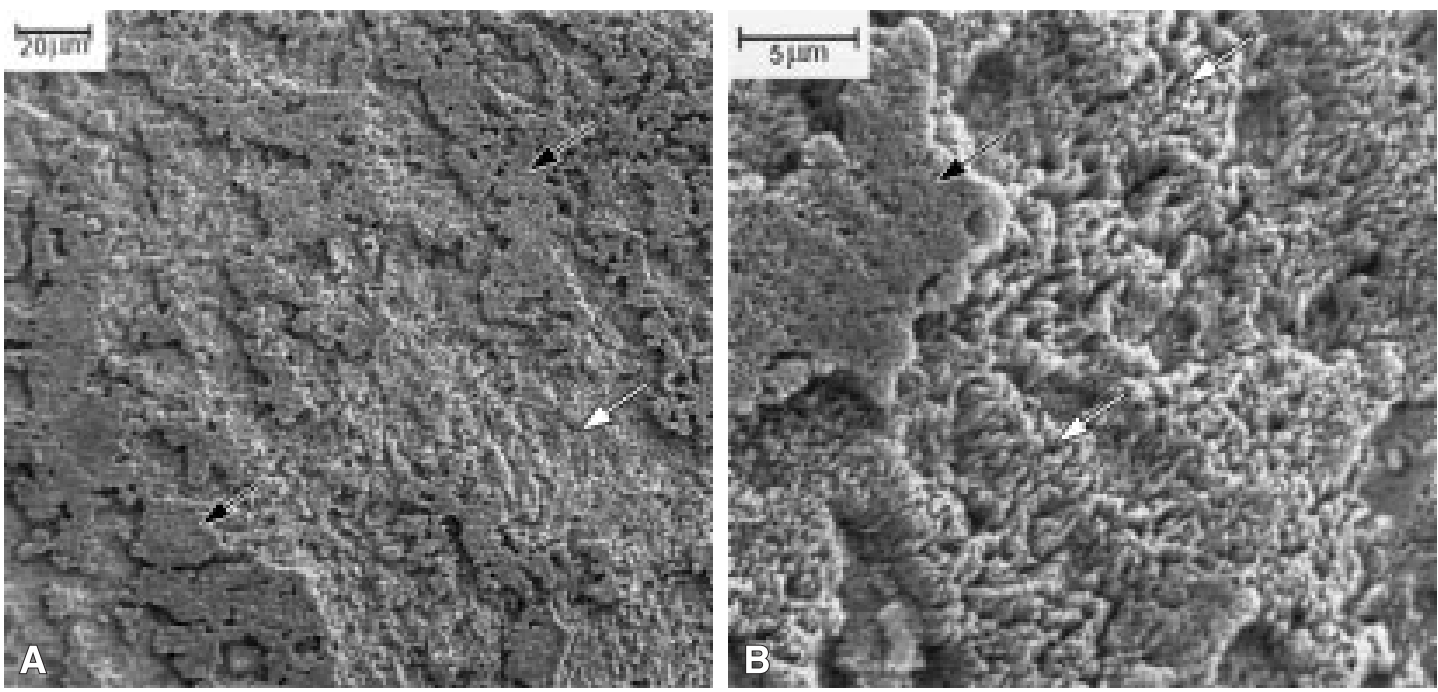

FIGURE 4 - Etched primary enamel (E) visualized under SEM. Black arrows indicate the original surface; white arrows indicate a new exposed enamel layer. A) $500 \mathrm{X}$; B) 3,000 X. 
Neves A de A, Castro R de A, Coutinho ET, Primo LG. Microstructural analysis of demineralized primary enamel after in vitro toothbrushing. Pesqui Odontol Bras 2002;16(2):137-143.

FIGURE 5 - Enamel brushed with a non-fluoridated dentifrice (EB) visualized under SEM. A) $500 \mathrm{X}$. The surface is smoothed down. B) 3,000 X. Black arrows indicate Tomes' process pits; white arrows, interrod enamel; dotted arrows, remnants of insoluble components of the dentifrice abrasive.
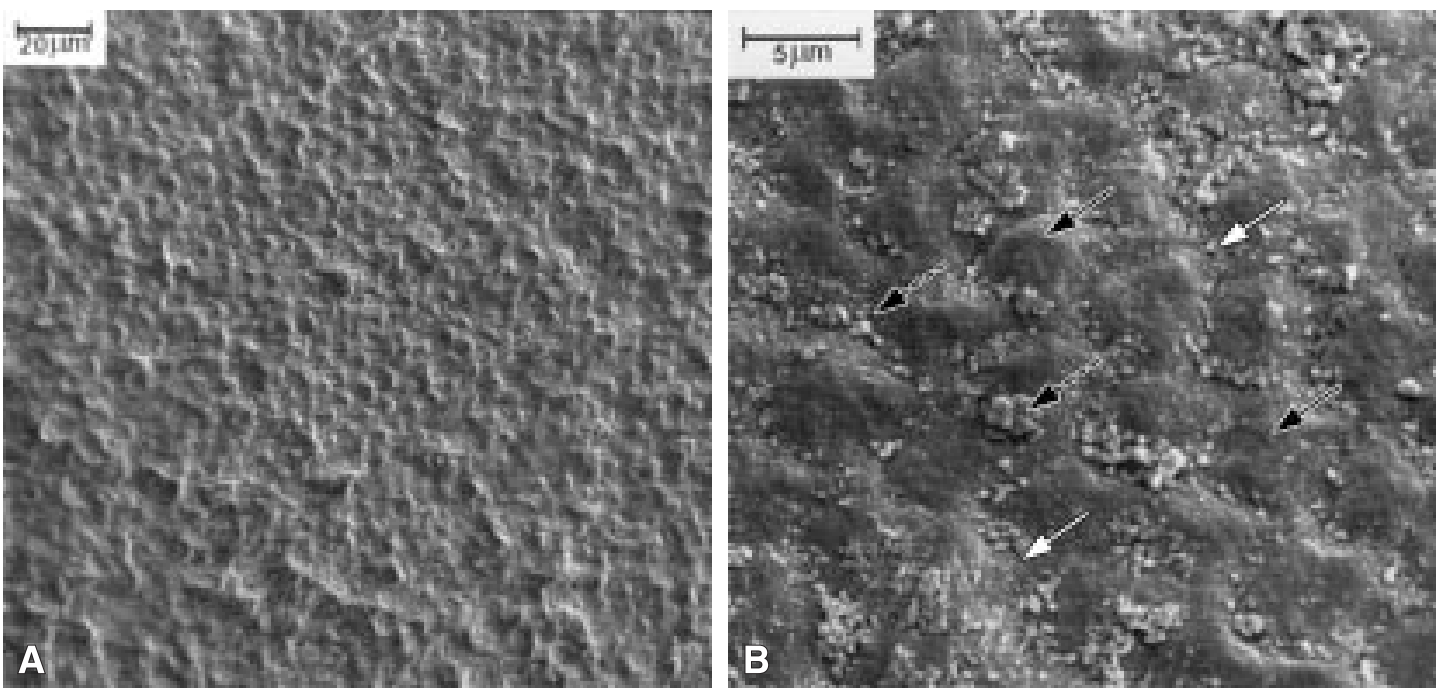

FIGURE 6 - Enamel brushed with a fluoridated dentifrice (EBF) visualized under SEM. A) 500 X. The surface is smoothed down. B) 3,000 X. Black arrows indicate Tomes' process pits; white

arrows, interrod enamel; dotted arrows, remnants of insoluble components of the dentifrice abrasive.
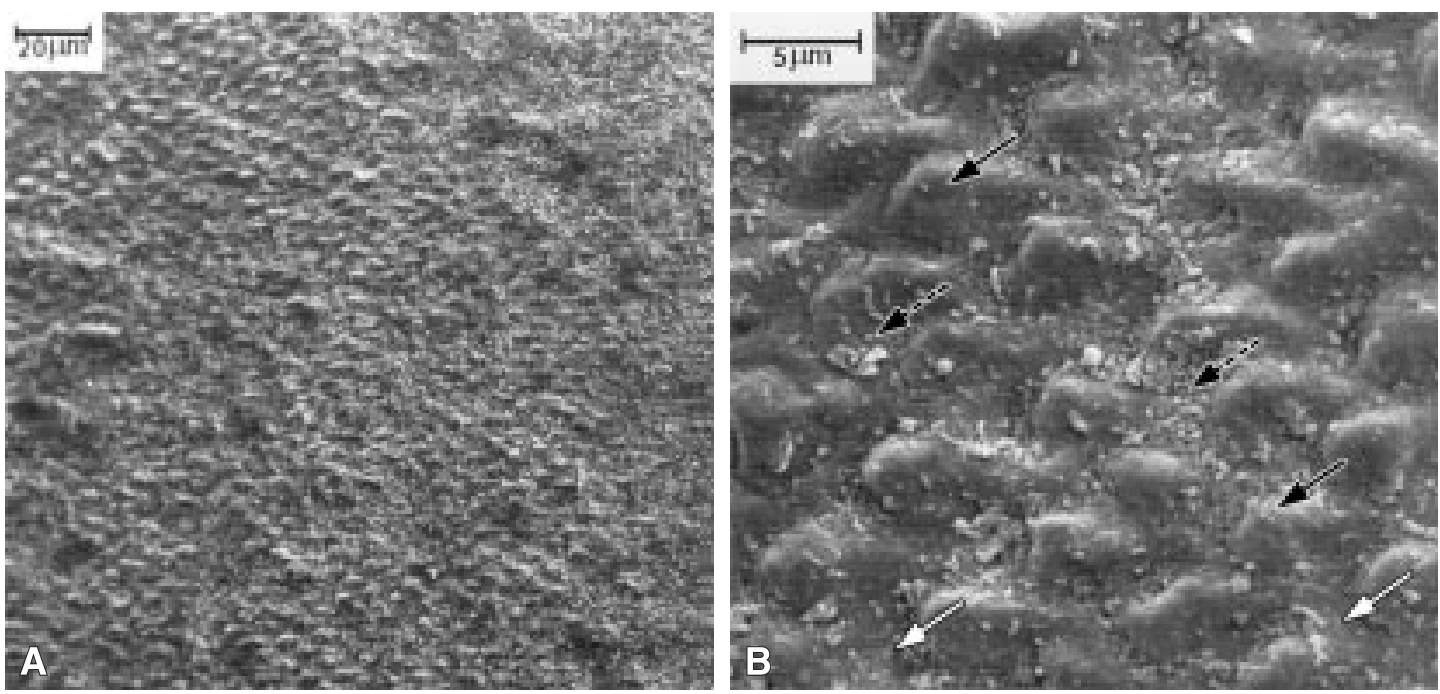

tected parts of the surface, such as in the grooves between Tomes' process pits (Figures 5B and 6B). No differences were found between groups EB and $\mathrm{EBF}$, as to surface morphology.

\section{DISCUSSION}

The smooth and scratched appearance of clinically sound enamel of erupted teeth, observed in the samples of the control group, was a common finding in other studies with permanent teeth carried out with SEM. Mannenberg ${ }^{17}$ (1960), using the replica technique, reported the appearance of new scratches, in vivo, after 4 weeks of toothbrushing with a dentifrice containing abrasive. Thylstrup, Fredebo $^{24}$ (1982) concluded that the scratched pattern and the smoothening of developmental irregularities are the gradual reaction of the enamel sur- face to the abrasion caused by toothbrushing. The anatomical structure of the tooth surface at the time of eruption, with the typical perikymata pattern, is gradually lost and replaced by a scratched pattern.

In this study, the acid etching technique was used to simulate the morphologic alterations that occur on the enamel surface when initial caries lesions are taking place or when enamel is etched but not covered with composites during restorative procedures. Although enamel caries is considered a subsurfacial lesion, as observed in polarized light microscopic studies ${ }^{6,15}$, correlated SEM studies show that together with subsurfacial porosity there is an intense dissolution of the outer enamel surface $^{11,14}$. In fact, according to Thylstrup et al. ${ }^{23}$ (1994), the chalky appearance of demineralized 
Neves A de A, Castro R de A, Coutinho ET, Primo LG. Microstructural analysis of demineralized primary enamel after in vitro toothbrushing. Pesqui Odontol Bras 2002;16(2):137-143.

enamel is enhanced by the irregular surface generated by direct erosion of the enamel surface, giving rise to a diffuse back-scattering of light. The method of demineralization chosen in this study intended to simulate the morphological alterations that take place on the enamel surface in those two clinical situations.

The pattern of demineralization in primary enamel is considered to be greatly altered by the presence of aprismatic enamel ${ }^{21}$. In fact, Costa et al. ${ }^{4}$ (1998) reported a random distribution of demineralization patterns in unerupted deciduous teeth etched with $35 \%$ phosphoric acid. However, Fava et al. $^{7}$ (1997), using the same technique, though with a larger number of samples, found a slightly greater prevalence of type II demineralization, which is in agreement with our findings.

As most studies report variations on the toothbrushing force applied by patients ${ }^{1,17}$, the standardization employed in this study intended to minimize possible differences in the results. Mannemberg ${ }^{17}$ (1960) found values ranging from 0.2 to $1 \mathrm{kgf}$ in the toothbrushing force applied by 48 individuals, while Björn, Lindhe ${ }^{1}$ (1966), studying 73 patients, found a mean maximum force of $0.45 \mathrm{kgf}$ during horizontal brushing. In this study, a force of $0.2 \mathrm{kgf}$ was chosen for being the most comfortable for the operator in the position of brushing the enamel blocks, while still in the range of the previously found values.

It is usually accepted that the etched enamel remineralizes few moments after being exposed to the oral environment ${ }^{9}$. Nevertheless, Garberoglio, Cozzani $^{8}$ (1979) observed that etched enamel surfaces do not show, microscopically, complete restitution of their structure after being exposed to the oral environment. After 90 days, the etched enamel cleaned off from the organic debris maintained its surface irregularities. The action of pumicing appeared to smooth the irregularities caused by the etching agent ${ }^{8}$.

Also, Hachiya et al. ${ }^{10}$ (1985) etched and stored extracted permanent teeth in artificial saliva for 1 month. During that period, a group was submitted to 15 brushing sessions (60 hand strokes in each session) with a dentifrice containing calcium carbonate. The enamel that was not brushed retained the irregularities produced by etching, while the brushed group presented rounded surface defects, although depressions were not completely eliminated. In our study, a smoother enamel surface was also present after brushing, and the ob- served depressions correspond to the interrod enamel of the brushed surfaces presented in Figures 5 and 6.

Holmen et al. ${ }^{13}$ (1987) observed, in high magnifications under SEM, that the carious enamel reexposed to oral mechanical forces showed removal of the external loosely packed crystals, corresponding, in broader terms, to the removal of the outer and demineralized surface. In the present study, the morphology of the brushed surfaces was characterized by a general leveling of the enamel surface and by the visualization of Tomes' process pits separated by smooth interrod enamel (Figures 5 and 6).

Although Head ${ }^{12}$ (1912) had previously stated that sound enamel shows insignificant wear to the dentifrice abrasive and its friction, while softened enamel may loose material from its surface, a different approach to the removal of the outer dissolved and porous demineralized enamel surface by toothbrushing was reported by Kuroiwa et al. ${ }^{16}$ (1994). The authors observed, in vivo, the gradual abrasion of demineralized enamel after toothbrushing with dentifrice. Samples brushed without dentifrice showed organic and mineral deposition, which was assumed to originate from salivary components and remnants of loose enamel crystallites smeared over the surface. The authors concluded that toothbrushing without dentifrice would remineralize etched enamel, while paste brushing would merely abrade the weakened superficial enamel layers, without remineralization.

While the subsuperficial characteristic of caries lesion is observed by means of polarized light, the remineralization of enamel is generally investigated by means of microhardness measurements ${ }^{20}$. The formation of an organic-mineral coating is a frequent observation ${ }^{8,16}$ that may contribute to the increasing hardness of the remineralized etched enamel. However, the clinical presence of such an organic coating over the enamel surfaces frequently leads to staining of tooth surfaces. Mannenberg $^{17}$ (1960) observed the appearance of a brownish film over tooth surfaces in patients using only a mouthwash during toothcleaning procedures. This fact supports the importance of some degree of abrasivity during toothcleaning procedures.

Although the fluoridated dentifrice used in this study contained MFP, which is supposed to depend on intra-oral hydrolysis to be effective, Bruun et $a .^{2}$ (1987) found out that enamel apatite significantly catalyses the breakdown of MFP. In our 
Neves A de A, Castro R de A, Coutinho ET, Primo LG. Microstructural analysis of demineralized primary enamel after in vitro toothbrushing. Pesqui Odontol Bras 2002;16(2):137-143.

study, the contact of the fluoridated dentifrice with enamel in vitro was considered as a catalyst to the breakdown of MFP.

Calcium fluoride-like material was not found. Such finding is in disagreement with those of Cruz et al. ${ }^{5}$ (1994). However, those authors had enamel surfaces treated for 24 hours with dentifrice supernatants, while no mechanical procedures was carried out. In the present study, mechanical abrasion or dissolution in artificial saliva probably impaired the observation of deposited calcium fluoride.

In spite of being generally acquainted that remineralization in the presence of fluoride restores the structure of the enamel surface, in this study, the appearances of surfaces brushed with either a fluoridated or non-fluoridated dentifrice were quite similar. However, using a morphological approach, it is not possible to preclude differences as to the chemical structures of samples brushed in the presence of fluoride or not. Corroborating this, Thylstrup, Bruun ${ }^{22}$ (1992) stated that the success of the individual caries control therapy based on the use of fluoridated dentifrices derives from mechanical plaque control combined to the maintenance of optimal levels of fluoride in the oral cavity.

In a morphological context, the leveling of the eroded surface of initial caries lesions or uncove-

\section{REFERENCES}

1. Björn H, Lindhe J. On the mechanisms of toothbrushing. Odont Rev 1966;17:9-16.

2. Bruun C, Giskov H, Thylstrup A. Intraoral hydrolysis of monofluorophosphate. Scand J Dent Res 1987;95:202-4.

3. Buonocore MG. A simple method of increasing the adhesion of acrylic filling materials to enamel surfaces. J Dent Res 1955;34:849-53.

4. Costa LRRS, Watanabe L, Fava M. Three-dimensional aspects of etched enamel in non-erupted deciduous teeth. Braz Dent J 1998;9:95-100.

5. Cruz R, Rolla G, Ogaard B. Alkali-soluble fluoride deposition on human enamel exposed to monofluorophosphate-containing toothpastes in vitro. Acta Odont Scand 1994;52:72-6.

6. Darling AI. Studies of the early lesion of enamel caries. Its nature, mode of spread, and points of entry. Brit Dent $J$ 1958;105:119-36.

7. Fava M, Watanabe L, Moraes FF, Costa LRRS. Observations on etched enamel in non-erupted deciduous molars. Rev Odont Univ São Paulo 1997;11:157-60.

8. Garberoglio R, Cozzani G. In vivo effect of oral environment on etched enamel: a scanning electron microscopic study. J Dent Res 1979;58:1859-65.

9. Gwinnett AJ, Buonocore MG. Adhesives and caries prevention. Brit Dent J 1965;119:77-80. red etched enamel, produced by mechanical treatment of the enamel (toothbrushing, professional toothcleaning), may have a special role in the fate of demineralized enamel since it renders a smoother surface, making it more difficult for bacteria to adhere and contributing to the disappearance of the chalky white appearance caused by erosion. In clinical situations, this fact may be misinterpreted as remineralization or re-incorporation of minerals into the enamel.

\section{CONCLUSION}

Brushing demineralized enamel surfaces with dentifrice led to smoothening of the outer dissolved surface by removing the irregularities caused by acid etching. There was no difference, as to the morphology of the enamel surface, between samples brushed with fluoridated and non-fluoridated dentifrices.

\section{ACKNOWLEDGMENTS}

The authors would like to thank the technical assistance of Noemia Rodrigues Gonçalves (Department of Biophysics, Federal University of Rio de Janeiro) and Maria de Fátima Lopes (Department of Material Sciences and Metallurgy, Pontifical Catholic University - Rio de Janeiro).

10. Hachiya Y, Takatsu T, Hosoda H, Fusayama T. A varnish to prevent etching unrestored enamel. J Prosth Dent 1985;53:46-50.

11. Haikell Y, Frank RM, Voegel JC. Scanning electron microscopy of the human enamel surface layer of incipient carious lesions. Caries Res 1983;17:1-13.

12. Head J. A study of saliva and its action on tooth enamel in reference to its hardening and softening. J Am Med Assoc 1912;59:2118-22.

13. Holmen L, Thylstrup A, Artun J. Surface changes during the arrest of active enamel carious lesions in vivo: a scanning electron microscopic study. Acta Odont Scand 1987;45:383-90.

14. Holmen L, Thylstrup A, Ogaard B, Kragh F. A scanning electron microscopic study of progressive stages of enamel caries in vivo. Caries Res 1985;19:355-67.

15. Holmen L, Thylstrup A, Ogaard B, Kragh F. Polarized light microscopic study of progressive stages of enamel caries in vivo. Caries Res 1985;19:348-54.

16. Kuroiwa M, Kodaka T, Kuroiwa M, Abe M. Brushing-induced effects with and without a non-fluoride abrasive dentifrice on remineralization of enamel surfaces etched with phosphoric acid. Caries Res 1994;28:309-14.

17. Mannenberg F. Appearance of tooth surface as observed in shadowed replicas. Odont Rev 1960; 11 suppl6:70-86. 
Neves A de A, Castro R de A, Coutinho ET, Primo LG. Microstructural analysis of demineralized primary enamel after in vitro toothbrushing. Pesqui Odontol Bras 2002;16(2):137-143.

18. Miura F, Nakagawa K, Masuhara E. New direct bonding system for plastic brackets. Am J Orthod 1971;59:350-61.

19. Monteiro Junior S, Andrada MAC, Baratieri LN. Remineralização de lesões cariosas incipientes. RGO 1985;33:185-9.

20. Silvestone LM. Remineralization phenomena. Caries Res 1977; 11 supp11:59-84.

21. Silverstone LM, Dogon IL. The effect of phosphoric acid on human deciduous enamel surfaces in vitro. J Int Assoc Dent Child 1976;7:11-5.

22. Thylstrup A, Bruun C. The use of dentifrices in the treatment of dental caries. In: Embery G, Rolla G. Clinical and biological aspects of dentifrices. Oxford: IRL Press; 1992. p.131-143.

23. Thylstrup A, Bruun C, Holmen L. In vivo caries models: mechanisms for caries initiation and arrestment. Adv Dent Res 1994;8:144-57.

24. Thylstrup A, Fredebo L. A method for studying surface coatings and the underlying enamel features in the scanning electron microscope. In: Frank RM, Leach SA. Surface and colloid phenomena in the oral cavity: methodological aspects. St. Louis: IRL Press; 1982. p.169-184.

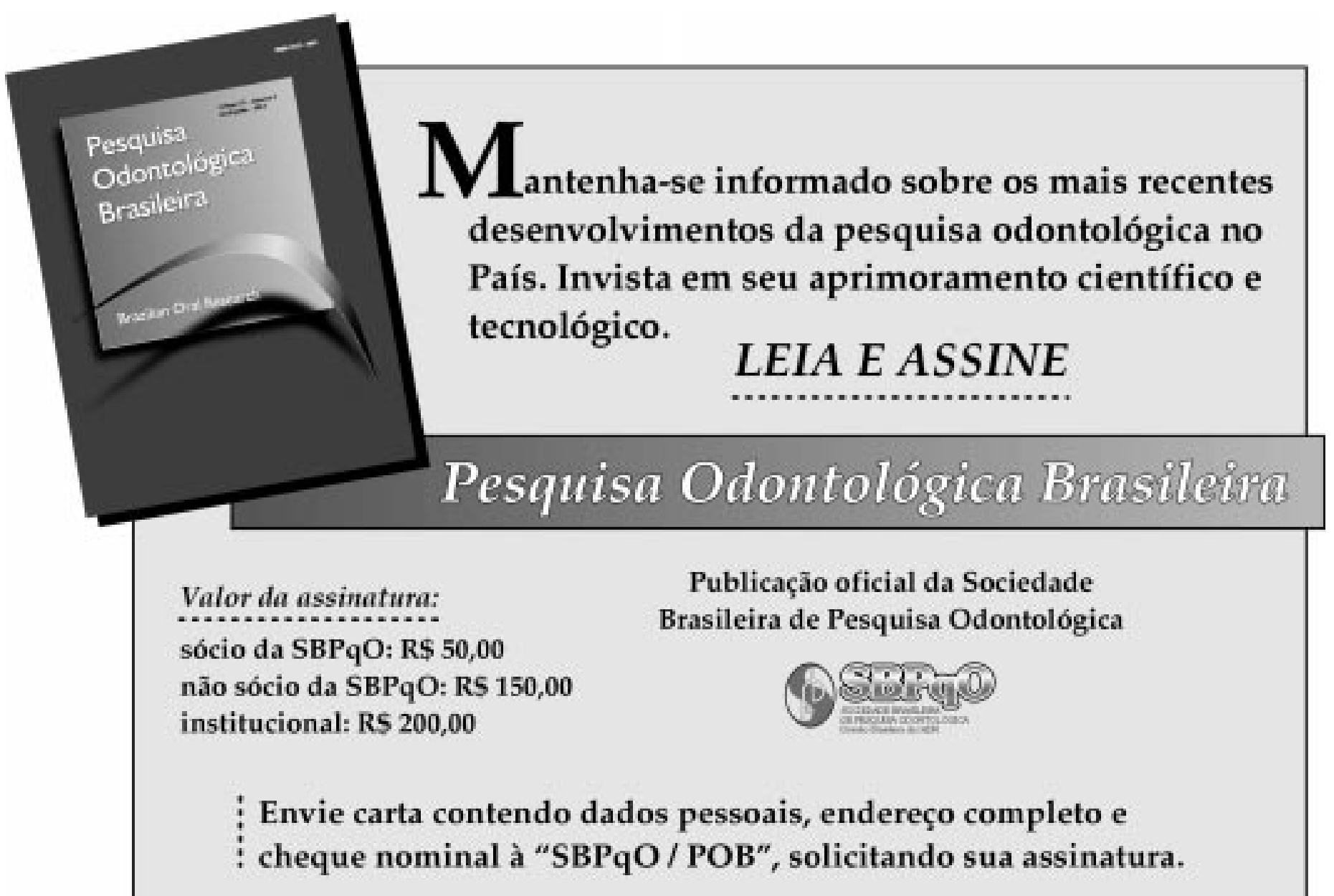

Endereco: $\mathrm{SBPqO}$ - Sociedade Brasileira de Pesquisa Odontológica

Av. Professor Lineu Prestes, 2.227 - CEP 05508-900 - Cidade Universitária São Paulo - SP - Tel./fax: (0xx11) 3091-7855 - e-mail: sbpqo@sbpqo.org.br 